\title{
Measurement of serum primary bile acid ratio by gas liquid chromatography and radioimmunoassay
}

\author{
C. R. PENNINGTON, Y. A. BAQIR, P. E. ROSS, J. MURISON, AND \\ IAN A. D. BOUCHIER
}

From the Department of Medicine, Ninewells Hospital and Medical School, Dundee DD1 9SY, UK

SUMMARY The application of a sensitive gas liquid chromatography (GLC) assay has enabled patients in different diagnostic groups to be differentiated on the basis of the ratio of the primary bile acids, cholic: chenodeoxycholic acid. Because this method is unsuitable for a routine clinical laboratory, the primary bile acid ratio (PBR) is determined by radioimmunoassay techniques (RIA), and the results were compared with GLC analysis. RIA provided comparable results in control subjects and patients with large-duct obstruction, but significantly higher PBR values were found in cirrhotic subjects.

Early studies on serum bile acids drew attention to the changes in bile acid ratios that occurred in hepatobiliary disease. The trihydroxy:dihydroxy ratio was noted to be increased in cholestasis and reduced in cirrhotics (Rudman and Kendall, 1957; Carey, 1958; Makino et al., 1969). Proportionately little deoxycholic acid is found in the serum of patients with hepatobiliary disease (Makino et al., 1969; Pennington et al., 1977); the trihydroxy:dihydroxy ratio, therefore, corresponds to the primary bile acid ratio (PBR). Unfortunately, the ratio was apparently of no diagnostic value because of the large overlap between clinical groups (Rudman and Kendall, 1957; Carey, 1958; Makino et al., 1969). With the methods used, however, it was not possible to measure serum bile acid values at or near the normal range. The application of a sensitive gas liquid chromatography (GLC) assay (Ross et al., 1977) enabled patients with cirrhosis and large-duct obstruction and control subjects to be separated on the basis of the PBR values (Pennington et al., 1977). Gas liquid chromatography is a lengthy procedure which is considered unsuitable for routine clinical laboratory use. On the other hand, radioimmunoassay (RIA) offers a rapid and accurate method for measuring bile acid conjugates (Simmonds et al., 1973; Murphy et al., 1974; Matern et al., 1976). This paper, therefore, compares the PBR values obtained by GLC and RIA of the same fasting venous specimen from patients with cirrhosis and large-duct obstruction and control subjects.

Received for publication 12 December 1978

\section{Patients and methods}

A $10 \mathrm{ml}$ venous sample of blood was obtained after a 12-hour fast from seven control subjects, 10 patients with cirrhosis, and 11 patients with large-duct obstruction. The diagnosis was established by histology in the cirrhotic group, while all patients with large-duct obstruction underwent laparotomy. The control subjects were clinically and biochemically normal and had given informed consent.

Serum bile acids were measured by a GLC method which has been described previously (Ross et al., 1977); $2 \mathrm{ml}$ of serum was analysed. After ethanol precipitation and enzyme hydrolysis, trifluoracetate methyl esters were formed and run on columns of OV210 on gas chrome Q. Conjugates of cholic acid and chenodeoxycholic acid were also measured by RIA (Baqir et al., 1979). Antisera were raised by injecting rabbits with bile acids linked to bovine serum albumin, and separation of bound tracer was achieved with ammonium sulphate.

Differences in the results obtained by the two methods were compared by Student's $t$ test for paired samples.

\section{Results}

The results are shown in the Table. The range of the PBR values in the control subjects was similar using GLC and RIA, and there was no significant difference in the results. The same applied to values obtained in patients with large-duct obstruction. With one exception (0.91) they were $\geqslant 1$ with both methods. Although in four of the 11 analyses marked 
Table PBR values obtained by GLC and RIA (mean $\pm 1 S D)$

\begin{tabular}{|c|c|c|c|c|c|c|}
\hline & \multicolumn{2}{|c|}{ Controls } & \multicolumn{2}{|c|}{ Cirrhosis } & \multicolumn{2}{|c|}{ Obstruction } \\
\hline & $G L C$ & $\boldsymbol{R} I A$ & $G L C$ & $R I A$ & $G L C$ & $R I A$ \\
\hline & $\begin{array}{l}0.9 \\
0.75 \\
0.87 \\
0.81 \\
0.72 \\
1.0 \\
0.65\end{array}$ & $\begin{array}{l}0.75 \\
0.88 \\
0.98 \\
0.88 \\
0.79 \\
0.9 \\
0.62\end{array}$ & $\begin{array}{l}0.45 \\
0.24 \\
0.30 \\
0.32 \\
0.49 \\
0.48 \\
0.17 \\
0.15 \\
0.22 \\
0.45\end{array}$ & $\begin{array}{l}0.46 \\
0.44 \\
0.45 \\
0.48 \\
0.72 \\
0.70 \\
0.40 \\
0.41 \\
0.32 \\
0.64\end{array}$ & $\begin{array}{l}1.9 \\
4.5 \\
3.3 \\
2.6 \\
1.7 \\
1.0 \\
1.0 \\
1.0 \\
1.3 \\
1.1 \\
1.4\end{array}$ & $\begin{array}{l}0.94 \\
2.5 \\
4.0 \\
2.7 \\
1.4 \\
0.91 \\
2.5 \\
1.0 \\
1.1 \\
1.1 \\
1.1\end{array}$ \\
\hline $\begin{array}{l}\text { Mean } \\
\pm 1 \text { SD }\end{array}$ & $\begin{array}{r}0.81 \\
\pm 0.12\end{array}$ & $\begin{array}{r}0.83 \\
\pm 0.12\end{array}$ & $\begin{array}{r}0.33 \\
\pm 0.13\end{array}$ & $\begin{array}{r}0.5^{*} \\
\pm 0.14\end{array}$ & $\begin{array}{r}1.9 \\
\pm 1.3\end{array}$ & $\begin{array}{r}1.8 \\
\pm 1.0\end{array}$ \\
\hline
\end{tabular}

$* \mathbf{P}<0.001$.

differences were observed between the methods, no overall trend was apparent. In all cirrhotic patients the PBR obtained by RIA was greater than that obtained by GLC. This difference was highly significant $(P<0.001)$ and was responsible for an overlap between the PBR values of the control and cirrhotic group when measured by RIA.

\section{Discussion}

A feature common to the RIA methods is crossreactivity between the cholyl conjugates and chenodeoxycholyl conjugate assays. Thus it was $10 \%$ in the method of Murphy et al. (1974) and as much as $26 \%$ in that reported by Spenney et al. (1977). The cross-reactivity in the method employed in this study is $11.7 \%$ (Baqir et al., 1979). We believe that it is this cross-reactivity that is responsible for the increased value of the PBR in cirrhotic subjects when measured by RIA compared with GLC. Cirrhotics are known to have proportionately very much more chenodeoxycholic acid than cholic acid (Makino et al., 1969; Pennington et al., 1977), and $11.7 \%$ of this chenodeoxycholic acid will be recorded as cholic acid by the current RIA method.

The results of the GLC and RIA assays are not strictly comparable. The former measures total conjugated and unconjugated bile acids, whereas the latter measures mainly conjugated bile acids. Variation in the extent of conjugation of individual bile acids may be a further factor causing a disparity in the results. However, in a preliminary comparison of total serum bile acid values measured by GLC,
RIA, and the enzymatic fluorimetric method, similar results were obtained by all three methods in most disease states (Ross et al., in preparation).

Although significant differences in the PBR values between the different groups persist when RIA methods are used, some overlap is observed between cirrhotic patients and control subjects. The practical application of the PBR has yet to be established.

\section{References}

Baqir, Y. A., Murison, J., Ross, P. E., and Bouchier, I. A. D. (1979). Radioimmunoassay of primary bile salts in serum. Journal of Clinical Pathology, 32, 560-564.

Carey, J. B., Jr. (1958). The serum trihydroxy-dihydroxy bile acid ratio in liver and biliary tract disease. Journal of Clinical Investigation, 37, 1494-1503.

Makino, I., Nakagawa, S., and Mashimo, K. (1969). Conjugated and unconjugated serum bile acid levels in patients with hepatobiliary diseases. Gastroenterology, 56, 1033-1039.

Matern, S., Krieger, R., and Gerok, W. (1976). Radioimmunoassay of serum conjugated cholic acid. Clinica Chimica Acta, 72, 39-48.

Murphy, G. M., Edkins, S. M., Williams, J. W., and Catty, D. (1974). The preparation and properties of an antiserum for the radioimmunoassay of serum conjugated cholic acid. Clinica Chimica Acta, 54, 81-89.

Pennington, C. R., Ross, P. E., and Bouchier, I. A. D. (1977). Serum bile acids in the diagnosis of hepatobiliary disease. Gut, 18, 903-908.

Ross, P. E., Pennington, C. R., and Bouchier, I. A. D. (1977). Gas liquid chromatographic assay of serum bile acids. Analytical Biochemistry, 80, 458-465.

Rudman, D., and Kendall, F. E. (1957). Bile acid content of human serum. 1. Serum bile acids in patients with hepatic disease. Journal of Clinical Investigation, 36, 530-537.

Simmonds, W. J., Korman, M. G., Go, V. L. W., and Hofmann, A. F. (1973). Radioimmunoassay of conjugated cholyl bile acids in serum. Gastroenterology, 65, 705-711.

Spenney, J. G., Johnson, B. J., Hirschowitz, B. I., Mihas, A. A., and Gibson, R. (1977). An ${ }^{125}$ I radioimmunoassay for primary conjugated bile salts. Gastroenterology, 72, 305-311.

Requests for reprints to: Dr C. R. Pennington, Department of Medicine, Ninewells Hospital and Medical School, Dundee DD1 9SY, UK. 